\title{
PENSAMENTO PÓS-MODERNO E A CIÊNCIA NO EXEMPLO DO PENSAMENTO DE MICHEL FOUCAULT
}

\author{
Post-modern thought and science in the example of the Michel Foucault's thinking
}

Manfredo Araújo de Oliveira*

Resumo: A postura teórica de Foucault se situa no contexto da crítica do pensamento fenomenológico-antropológico de uma filosofia marcada pela "centralidade do sujeito", através de uma "ontologia do impensado": toda a conduta do sujeito é dirigida por um esquema simbólico, por um sistema que muda com as idades e as sociedades. Neste contexto, as ciências humanas constituem objeto privilegiado de análise: não se trata apenas de situar um discurso no contexto de outros discursos, mas de tematizar as práticas ocultas que estão nas raízes de sua emergência. Elas fazem parte, com outras práticas discursivas, de complexos de poder: o poder informa o saber, o sistema do saber reproduz o sistema do poder e o projeto genealógico de Foucault de uma escrita da história enquanto anti-ciência tem como objetivo apresentar uma proposta alternativa de saber às ciências humanas vinculadas ao pensamento antropológico da modernidade.

Palavras-chave: Foucault. Ciência. Saber. Poder. Antropologia.

\begin{abstract}
The theoretical stance of Foucault is situated in the context of the critique of the phenomenological-anthropological thought of a philosophy characterized by the "centrality of the subject" through an "ontology of the unthought": entire conduct of the subject is guided by a symbolic scheme by a system which changes with the ages and societies. The human sciences is privileged object of analysis in this context: the point is not to situate a speech in the context of other discourses but it is to broach the issue of the occult practices that are at the roots of their emergence. They belong with other discursive practices to complexes of power: the power informs the knowledge, the system of the knowledge reproduces the system of power and Foucault's genealogical project of writing of history as antiscience aims to present an alternative proposal of knowledge to the human sciences related to the anthropological thought of modernity.
\end{abstract}

Keywords: Foucault. Science. Knowledge. Power. Anthropology.

\footnotetext{
* Professor titular da Universidade Federal do Ceará (UFC). Contato: manfredo.oliveira@uol.com.br
}

\begin{tabular}{|c|c|c|c|c|c|}
\hline intuitio & $\begin{array}{c}\text { ISSN } \\
1983-4012\end{array}$ & Porto Alegre & Vol.7- No.2 & $\begin{array}{c}\text { Novembro } \\
2014\end{array}$ & p. 06-19 \\
\hline
\end{tabular}


Pode-se situar o que se denominou de pensamento pós-moderno precisamente no seio da "crítica da razão" que marca nossos dias ${ }^{1}$. Neste contexto, a razão emerge como repressiva, frente aos indivíduos e suas aspirações à autonomia, e destruidora frente à natureza, eurocêntrica, falocêntrica e fundamentalmente cega ao outro. $\mathrm{O}$ resultado de tudo isto é que nossa civilização, basicamente determinada pela razão, no fundo conduz a uma guerra civil quotidiana contra a espécie "Homem". É neste contexto da crítica contemporânea à razão que podemos situar a postura do pensamento pósmoderno frente à ciência, embora no caso de Foucault, que vamos examinar, não haja propriamente a pretensão de articular uma crítica da razão pelas razões que mostraremos mais adiante.

\section{A posição das ciências humanas no contexto dos saberes}

A postura teórica de Foucault ${ }^{2}$ se situa claramente no contexto da crítica à filosofia moderna da subjetividade, daquilo que ele chamará de "ilusão antropológica", ou seja, trata-se da crítica do pensamento fenomenológico-antropológico hegemônico no século passado ${ }^{4}$ a que ele foi levado em primeiro lugar por seus contactos com o estruturalismo francês ${ }^{5}$ que em princípio é um discurso radicalmente crítico da postura de uma filosofia marcada pela "centralidade do sujeito" e enquanto tal crítico da modernidade ${ }^{6}$. Neste sentido, o pensamento de Foucault pode ser situado no contexto do grande debate da filosofia francesa do século XX a respeito do humanismo e do anti-humanismo. Sua pretensão é abrir o horizonte para uma forma alternativa de pensar: "em nossos dias só se pode pensar no vazio do homem desaparecido... pois este vazio nada mais é do que a abertura de um espaço em que é enfim possível pensar de novo ${ }^{7}$ ".

Já nos anos $60^{8}$, Foucault defende uma posição em que a subjetividade perde o poder determinante no pensamento que lhe havia sido atribuído na modernidade. Ele chega a falar mais tarde de uma "ontologia do impensado", do implícito, do não atual, enquanto fundamento indisponível do saber que põe fora do circuito a primazia do "eu penso"." Para Foucault ${ }^{10}$ toda a conduta do sujeito é dirigida por uma estrutura teórica, por uma ordenação de símbolos ${ }^{11}$, por um esquema simbólico, por um sistema que muda com as idades e as sociedades ${ }^{12}$, por uma "épistéme" que subjaz ao Eu, ao

\footnotetext{
${ }^{1}$ Cf. WELSCH W. Vernunft. Die zeitgenössische Vernunftkritik und das Konzept der transversalen Vernunft, Frankfurt am Main: Suhrkamp, 2a. Ed., 1996, p. 30.

${ }^{2}$ Cf. DREYFUS H./RABINOW P., Michel Foucault, uma trajetória filosófica: para além do estruturalismo e da hermenêutica, Rio de Janeiro: Forense Universitária, 1995.

${ }^{3}$ Cf. FOUCAULT M., Qu'est-ce que les Lumières?, in: Dits et Écrits 1954-1988, Paris: Gallimard, 1994, p. 67988.

${ }^{4}$ Foucault em suas entrevistas cita como hegemônicas no contexto do pensamento francês a fenomenologia, o marxismo e a história das ciências. Para ele, seu pensamento se situa no cruzamento destas correntes.

5 Habermas fala de "desmascaramento crítico-racional" das ciências humanas no título de seu texto sobre Foucault. Cf. HABERMAS J., Vernunftkritische Entlarvung der Humanwissenschaften: Foucault, in: Der philosophische Diskurs der Moderne. Zwölf Vorlesungen. Frankfurt am Main: Suhrkamp, 2a . Ed., 1985, p. 279312.

${ }^{6}$ Habermas fala de um parentesco entre a arqueologia das ciências humanas e a crítica da metafísica da modernidade de Heidegger. As "episteme" ou "formas de saber" da renascença, da idade clássica e da modernidade em Foucault enquanto estádios na formação da concepção de ser centrada no sujeito são semelhantes ao que Heidegger analisou de Descartes a Nietzsche. No entanto ele não exclui a concepção da "historia do ser" de Heidegger do círculo do sujeito autocentrado da modernidade. Cf. HABERMAS J., Der philosophische Diskurs der Moderne, op. Cit., p. 313.

${ }^{7}$ Cf. FOUCAULT M., Les mots et les choses. Une archéologie des sciences humaines, Paris: Gallimard, 1966, p. 353.

${ }^{8}$ Cf. BRANCO G. C, Michel Foucault: os Direitos do Homem, in: AGUIAR O. A./MORAES PINHEIRO C. de/FRANKLIN K (orgs.) Filosofia e Direitos Humanos, Fortaleza: Editora UFC, 2006, p. 143: “... Foucault surge, nos anos sessenta, com estrondoso sucesso, anunciando o começo de uma forma nova de pensar, que tem no sistema seu objeto privilegiado de análise, e que recusa todo humanismo".

${ }^{9}$ Cf. FOUCAULT M., Les mots et les choses, op. Cit., p. 337.

${ }^{10}$ Numa entrevista de 1966 retomada numa publicação posterior. Cf. FOUCAULT M., Dits et Écrits, Paris: Gallimard, 1994, p. 515.

${ }^{11}$ Cf. FOUCAULT M., Les mots et les choses, op.cit., p. 11.

${ }^{12}$ Cf. FOUCAULT M., Dits et Écrits, op. Cit., p. 515.
}

\begin{tabular}{|c|c|l|l|c|c|}
\hline intuitio & $\begin{array}{c}\text { ISSN } \\
1983-4012\end{array}$ & Porto Alegre & Vol.7- No.2 & $\begin{array}{c}\text { Novembro } \\
2014\end{array}$ & p. 06-19 \\
\hline
\end{tabular}


Cogito.

Trata-se aqui de um pensamento sem sujeito nem identidade, mas que sobre-determina o eu, a consciência, a identidade e torna possível a seus participantes pensar algo enquanto algo. Está em jogo um conjunto de relações que podem unir numa época dada as práticas discursivas que possibilitam figuras epistemológicas, ciências e eventualmente sistemas formais ${ }^{13}$, ou seja, trata-se de um a priori histórico $^{14}$. Aqui se revela uma ligação profunda com as teorias estruturalistas. Para M. Frank, Foucault revisou depois sua ligação ao estruturalismo, quando se deu conta de que o estruturalismo forneceu implicitamente o modelo para a descrição da forma clássica de saber do representacionalismo semiótico. Desta forma uma superação estruturalista do pensamento antropocêntrico não significaria propriamente uma superação da modernidade ${ }^{15}$.

Dessa forma, tudo é considerado no campo destas ordenações que tomam o lugar que a filosofia moderna havia atribuído ao sujeito. "Para o sujeito, tomar consciência de si vai significar agora se dar conta de suas dependências constitutivas: qualquer visão do mundo é pré-estruturada, isto é, as significações e os conceitos de que nos servimos para interpretar o mundo não são expressão de nossas intenções. Não somos nós que os instituímos, mas antes, como diz Foucault ${ }^{16}$, é uma visão que nos é imposta pelo todo discursivo de uma época" ${ }^{17}$.

No prefácio de "As Palavras e as Coisas"18, Foucault diz que o saber que ele tem em mira não tem a ver com a história das ideias ou das ciências, mas se esforça por encontrar a esfera a partir de onde os conhecimentos e as teorias são possibilitados. Trata-se de tematizar o a priori histórico, as condições contingentes de constituição dos saberes e consequentemente as diferentes formas de saber que se sucedem historicamente numa história que se constitui por uma série de rupturas entre as quais nenhuma razão teleológica pode estabelecer continuidade.

É por esta razão que esta análise se chama "arqueologia", ou seja, ela é a teoria que esclarece os a priori históricos dos discursos hegemônicos nas diferentes épocas ${ }^{19}$, numa palavra, ela explicita o fundamento da formação e da transformação dos discursos ${ }^{20}$, isto é, aquele sistema de enunciados surgido na história que na "Arqueologia do saber" Foucault afirma que dá consistência ao conjunto de sentenças por ele dominado através de regras e protegido de dissolução num outro sistema de enunciados ${ }^{21}$.

M. Frank ${ }^{22}$ vê em Foucault a influência clara do pensamento de Heidegger de uma "história do ser" sob a forma de imagens do mundo que são pré-dadas ao nosso pensamento e à nossa compreensão sem que possamos dispor delas o que significa um passo importante para a superação da centralidade do sujeito na filosofia uma vez que aqui a subjetividade é pensada enquanto situada e condicionada por ordens simbólicas instituídas.

${ }^{13}$ Cf. FOUCAULT M., L'archéologie du savoir, Paris: Gallimard, 1969, p. 250.

${ }^{14}$ M. Frank vê aqui analogias com o que o Romantismo chamou de o "Histórico Transcendental". Cf. FRANK M., Was ist Neostrukturalismus?, op. Cit., p. 211-212.

${ }^{15}$ Cf. FRANK M., Was ist Neostrukturalismus?, Frankfurt am Main: Suhrkamp, 1983, p. 174-215.

${ }^{16}$ Cf. FOUCAULT M., Les mots et les choses, op. cit., p. 12. L. Althusser usa uma metáfora semelhante. Cf. ALTHUSSER L., Lire le Capital, vol. I, Paris: Maspero, 1968, p. 25, 28.

${ }^{17}$ Cf. OLIVEIRA M. A. de, Pós-Modernidade: abordagem filosófica, in: TRASFERETTI J./GONÇALVES P. S.L (orgs.), Teologia na Pós-Modernidade. Abordagens epistemológica, sistemática e teórico-prática, São Paulo:Paulinas, 2003, p. 35.

${ }^{18}$ Cf. FOUCAULT M., Les mots et les choses, op. Cit., p. 13.

${ }^{19}$ Cf. KREMER-MARIETTI A., Introdução ao Pensamento de Michel Foucault, Rio de Janeiro: Zahar Editores, 1977, p. 41: "Lançada à pesquisa do a priori histórico, a arqueologia denuncia um a priori que condiciona a realidade dos enunciados, a priori que a história-ciência teria negligentemente deixado de lado ao ignorar a especificidade da história do discurso e a do discurso da história".

${ }^{20}$ Foucault reconhece que usou este conceito central em seu pensamento em três sentidos: domínio geral de todos os enunciados, grupo individualizável de enunciados, prática regrada que dá conta de certo número de enunciados. Cf. FOUCAULT M., L'archéologie du savoir, op. cit., p. 106.

${ }^{21}$ Cf. FRANK M., Was ist Neostrukturalismus?, op. Cit., p. 216.

${ }^{22}$ Cf. FRANK M., Was ist Neostrukturalismus?, op. Cit., p. 135.

\begin{tabular}{|c|c|c|c|c|c|}
\hline intuitio & $\begin{array}{c}\text { ISSN } \\
1983-4012\end{array}$ & Porto Alegre & Vol.7- $\mathrm{N}^{\circ} .2$ & $\begin{array}{c}\text { Novembro } \\
2014\end{array}$ & p. 06-19 \\
\hline
\end{tabular}


Nossa visão do mundo e de nós mesmos nos é sobreposta pelo a priori irrecusável de uma estrutura epistêmica ${ }^{23}$. Na medida, porém, em que se trata do a priori de uma estrutura epistêmica Foucault efetiva também na realidade uma substituição da investigação das conexões de sentido própria à hermenêutica pela análise de estruturas anônimas e não portadoras de sentido ${ }^{24}$ e mais tarde pela investigação das práticas de poder subjacentes a estas estruturas.

Para Foucault, aquilo que a filosofia moderna da subjetividade considerou uma atividade do sujeito, sua capacidade de perceber as coisas, é na realidade um efeito secundário do que ele denomina "a formação discursiva de uma época", do espaço em que o sujeito pode tomar posição para falar dos objetos, do domínio em que o sujeito está necessariamente situado ${ }^{25}$ e que muda através da história. Assim, o campo de relações que constitui uma formação discursiva permite ao sujeito nele inserido conhecer coisas, interagir simbolicamente com elas, ou seja, interpretar o mundo. O sujeito se revela assim necessariamente situado e dependente sem poder jamais ser considerado o responsável principal pelo campo discursivo. Supera-se, portanto, a subjetividade como princípio mostrando sua finitude radical e, portanto, sua incapacidade de uma transparência plena, o que se revela em suas dependências estruturais ${ }^{26}$.

Efetiva-se aqui, de qualquer modo, claramente uma mudança de centralidade: da centralidade da subjetividade para a centralidade do sistema, que agora emerge como o campo de inteligibilidade fundamental: "O sistema, em posição de fundamento, torna o ser ou o sujeito da consciência meros fenômenos de superfície ${ }^{27}$. É essa tese básica que fundamenta teoricamente o anti-humanismo ${ }^{28} \mathrm{de}$ Foucault que neste sentido é em primeiro lugar um problema teórico, embora se articule depois como imperativo político uma vez que a tarefa política fundamental de nossas sociedades é "nos desembaraçarmos definitivamente do humanismo ${ }^{29}$ ". Pode-se certamente também citar Influências fortes de Nietzsche ${ }^{30}$, Heidegger ${ }^{31}$ e Bataille, mas é importante lembrar que Foucault se entende a si mesmo em primeiro lugar como um historiador das ciências enquanto discípulo de Bachelard.

Foucault de fato toma as ciências humanas como objeto privilegiado de suas reflexões sobre as ciências, mas situando-as no quadro englobante dos saberes no contexto de sua problemática básica sobre sua formação histórica, ou seja, sobre suas condições discursivas de possibilidade. Seu ponto de partida é a afirmação de base de que o modo de ser do homem como ele é pensado na modernidade lhe permite exercer dois papeis fundamentais ${ }^{32}$ : ele é por um lado o fundamento de todas as positividades, ou seja, das ciências empíricas, portanto, uma grandeza transcendental enquanto constituinte dos saberes empíricos e, por outro lado, presente ele mesmo nos elementos das coisas empíricas.

Daí a diferenciação de dois domínios de saber: por um lado temos a filosofia transcendental que busca as condições de possibilidade do conhecimento enquanto tal e que as explica a partir das produções de um sujeito não-empírico ${ }^{33}$. Por outro lado, há um pensamento "que interroga as condições de uma relação entre as representações do lado do ser mesmo que se encontra representado" ${ }^{34}$. Aqui os princípios que fundam a unidade do ente representado pelo saber embora não possam ser

${ }^{23}$ Cf. FRANK M., Was ist Neostrukturalismus?, op. Cit., p. 197.

${ }^{24}$ Cf. HABERMAS J., Der philosophische Diskurs der Moderne, op. Cit., p. 323.

${ }^{25}$ Cf. FOUCAULT M., L'archéologie du savoir, op. cit., p. 238-239.

${ }^{26}$ Cf. OLIVEIRA M. A. de, Pós-Modernidade: abordagem filosófica, in: TRASFERETTI J./GONÇALVES P. S.L (orgs.), Teologia na Pós-Modernidade, op. Cit., p. 35.

${ }^{27}$ Cf. BRANCO G. C, Michel Foucault: os Direitos do Homem, op. Cit., p. 144.

${ }^{28}$ Castelo Branco chama a atenção para a grande influência que teve L. Althusser no pensamento francês antihumanista, inclusive no pensamento de Foucault, sobretudo, por sua interpretação do pensamento de Marx como "anti-humanismo" teórico. Cf. BRANCO G. C, Michel Foucault: os Direitos do Homem, op. Cit., p. 147-149.

${ }^{29}$ Cf. FOUCAULT M., Dits et Écrits, op. Cit., p. 515.

${ }^{30}$ Cf. MARTON S, Foucault leitor de Nietzsche, in: RIBEIRO R. J., Recordar Foucault, São Paulo: Brasiliense, 1985, p. 36-46.

${ }^{31}$ Pouco tempo antes de sua morte Foucault afirmou que Heidegger foi para ele "sempre o filósofo essencial". Cf. FOUCAULT M., Le retour de la morale, in: Les Nouvelles, 28.6 e 5.7.1984, p. 40. Welsch afirma que Foucault acolheu intensivamente o pensamento de Heidegger, embora o cite raramente. Cf. WELSCH W. Vernunft. Die zeitgenössische Vernunftkritik, op. Cit. p. 165.

${ }^{32}$ Cf. FOUCAULT M., Les mots et les choses, op. Cit., p. 355.

${ }^{33}$ Cf. FOUCAULT M., Les mots et les choses, op. Cit., p. 256.

${ }^{34}$ Cf. FOUCAULT M., Les mots et les choses, op. Cit., p. 257.

\begin{tabular}{|c|c|c|c|c|c|}
\hline intuitio & $\begin{array}{c}\text { ISSN } \\
1983-4012\end{array}$ & Porto Alegre & Vol.7- No.2 & $\begin{array}{c}\text { Novembro } \\
2014\end{array}$ & p. 06-19 \\
\hline
\end{tabular}


objetivados, são, contudo, princípios objetivos uma vez que fundam a conexão concreta do mundo de experiência. É isto que Foucault denomina de "transcendentais": o trabalho, a vida e a linguagem ${ }^{35}$.

Numa palavra, o ser humano é igualmente empírico e transcendenta ${ }^{36} \mathrm{e}$ é este fato que contém o a priori histórico que desde o século XIX vai constituir o elemento decisivo para o estabelecimento das ciências humanas. O discurso se torna ao mesmo tempo empírico (finitude, historicidade) e transcendental (fundamentação). Neste contexto emergiu a antropologia com o objetivo de conciliar em si mesma estas duas posturas de saber ${ }^{37}$.

Uma consideração de entrada a respeito das ciências humanas é que a palavra homem ou natureza humana designa sem dúvida um campo do mundo, mas ainda vazio. Nos séculos XVII e XVIII ninguém encontrou propriamente o homem, porque ele não existia ${ }^{38}$. Desta forma, o homem enquanto objeto de conhecimento como ele é trabalhado nas ciências humanas é produção recente, ele é propriamente uma criação do Romantismo na passagem do século XVIII para o século XIX. Como afirma Foucault: "Uma coisa em todo caso é certa: o homem não é nem o mais velho nem o mais constante problema que se tem colocado ao saber humano ${ }^{39}$ ".

As ciências humanas só apareceram na cultura ocidental, quando o ser humano se constituiu como o que era preciso pensar e o que existia para saber, ou seja, quando se estabeleceu a centralidade do sujeito humano no saber. Este é o grande acontecimento do século XIX: pela primeira vez depois de que existem seres humanos e que eles vivem em sociedade, o homem se tornou objeto de ciência. $\mathrm{O}$ que há de novo aqui é que se percebeu a necessidade de refletir sobre o ser humano como fundamento das diferentes ciências que se desenvolviam: ele emerge agora como aquele a partir de onde todo e qualquer saber é constituído o que vai produzir um eterno debate entre as ciências humanas e as demais ciências que, então, precisam defender-se contra os antropologismos, ou seja, contra os psicologismos, os sociologismos, etc. ${ }^{40}$

Como se situam, então, as ciências humanas neste novo contexto? Para Foucault, o domínio do saber moderno é um espaço volumoso e aberto segundo três dimensões básicas ${ }^{41}$ : 1) As ciências matemáticas e físicas para as quais a ordem é sempre um encadeamento dedutivo e linear de proposições evidentes e verificadas; 2) As ciências empíricas da vida (biologia), da linguagem (linguística) e da produção e consumo das riquezas (economia) que põem em relação elementos descontínuos, mas análogos; 3) A reflexão filosófica que se situa na consideração da finitude radical.

As ciências humanas são excluídas deste "triedro epistemológico" pelo menos no sentido de que elas não são encontráveis em nenhum destes níveis justamente porque seu lugar específico é nos interstícios destes saberes. Assim, elas se constituem como planos intermediários que unem entre si todas as dimensões do espaço epistemológico: as ciências dedutivas, as ciências empíricas e a reflexão filosófica. É esta situação que as faz entrar em relação com todas as outras formas de saber, mas ao mesmo tempo em risco constante de produzir os psicologismos, sociologismos, etc. Por esta razão hoje o maior perigo interior ao saber é a antropologização, uma das consequências da complexidade da configuração epistemológica em que as ciências humanas estão colocadas. Se o homem não está mais no centro do universo, as ciências humanas, contudo, permanecem intermediários perigosos no reino do saber. Apesar de suas incertezas e de sua precariedade, elas continuam levantando pretensões

\footnotetext{
${ }^{35}$ Cf. FOUCAULT M., Les mots et les choses, op. Cit., p. 257: "O trabalho, a vida e a linguagem aparecem como"transcendentais" que tornam possível o conhecimento objetivo dos seres vivos, das leis da produção, das formas da linguagem".

${ }^{36}$ Cf. FOUCAULT M., Les mots et les choses, op. Cit., p. 331.

${ }^{37}$ Cf. FOUCAULT M., Les mots et les choses, op. Cit., p. 352. Foucault vê esta tensão na própria antropologia de Kant. Cf. TERRA R., Foucault leitor de Kant: da Antropologia à Ontologia do presente, in: Analytica, vol. 2, n. 1 (1997)83: “... ela é conhecimento do homem em um movimento que o objetiva, no nível de seu ser natural e no conteúdo de suas determinações animais; mas ela é o conhecimento do conhecimento do homem, num movimento que interroga o sujeito sobre ele mesmo, sobre seus limites e sobre aquilo que ele autoriza no saber que dele se tem (118). A tensão do empírico e do crítico permanece, e é essa tensão que será desfeita nas antropologias contemporâneas". P. 84: "Para Foucault, na tese, Kant teria transformado a fundo a questão antropológica, mas não teria conseguido resolver a ambiguidade da relação entre o empírico e o transcendental".

${ }^{38}$ Cf. FOUCAULT M., Les mots et les choses, op. Cit., p. 319.

${ }^{39}$ Cf. FOUCAULT M., Les mots et les choses, op. Cit. p. 398.

${ }^{40}$ Cf. FOUCAULT M., Les mots et les choses, op. Cit., p. 356-357.

${ }^{41}$ Cf. FOUCAULT M., Les mots et les choses, op. Cit., p. 358.
}

\begin{tabular}{|c|c|c|c|c|c|}
\hline intuitio & $\begin{array}{c}\text { ISSN } \\
1983-4012\end{array}$ & Porto Alegre & Vol.7- No.2 & $\begin{array}{c}\text { Novembro } \\
2014\end{array}$ & p. 06-19 \\
\hline
\end{tabular}


universalizantes que as tornam um perigo permanente.

O que caracteriza as ciências humanas ${ }^{42}$ em sua forma de saber é que o ser humano é aquele ser vivo que do interior da vida a que ele pertence e pela qual ele é perpassado em todo o seu ser constitui representações graças a que ele vive e a partir das quais ele detém esta estranha capacidade de poder representar justamente a vida. Então, o objeto das ciências humanas é este ser que do interior das formas de produção que comandam toda sua vida forma a representação dessas necessidades, da sociedade pela qual, com a qual ou contra a qual ele as satisfaz. Nas ciências humanas o ser humano se manifesta como aquele que é o fundamento de todas as positividades: "o ser humano se tornava aquilo a partir de que todo conhecimento podia ser constituído em sua evidência imediata e não problematizada; ele se tornava a fortiori aquilo que autoriza o questionamento de todo o conhecimento do homem ${ }^{43}$ ".

A representação é, assim, o elemento decisivo para a configuração das ciências humanas. Seu objeto, portanto, não é o que o ser humano é por natureza, mas antes a análise que se estende entre o que é o ser humano em sua positividade (ser vivo, trabalhador, falante) e o que permite a esse ser saber o que é a vida, e em que consistem a essência do trabalho e suas leis e de que maneira ele pode falar. Numa palavra, elas se situam na esfera da possibilitação dos saberes empíricos no próprio ser do ser humano e enquanto tais levantam a pretensão de purificar o inteligível de todo empírico, contingente e particular $^{44}$. Desta forma para Foucault as ciências humanas são transcendentalmente orientadas e enquanto tais se perguntam pelas condições de possibilidade de tal saber. Assim se pode dizer que "há ciência humana não em qualquer lugar em que se põe a questão do homem, mas em qualquer lugar em que se analisam, na dimensão própria ao inconsciente, normas, regras, conjuntos significantes que manifestam à consciência as condições de suas formas e de seus conteúdos ${ }^{45}$ ".

Elas mostram como se abre o espaço da representação, como o ser humano pode ter a ver em seu ser com as coisas que ele conhece e conhecer as que determinam na positividade seu modo de ser. Assim, as ciências humanas desenvolvem a finitude, a relatividade, a perspectiva, do ser humano, numa palavra, a erosão indefinida do tempo ${ }^{46}$ na exterioridade do conhecimento e enquanto tais elas estão em relação às ciências empíricas em que o ser humano é objeto numa posição que Foucault denomina de "redobramento", ou seja, numa posição "meta-epistemológica".

\section{A raiz oculta das ciências humanas}

Foucault não estava interessado apenas em situar os discursos das ciências humanas no contexto mais abrangente dos discursos humanos, mas seu objetivo foi desde o início investigar a vinculação entre discursos e práticas ${ }^{47}$ no sentido de explicitar as próprias raízes internas dos discursos, ou seja, o a priori contingente e histórico que constitui sua condição de possibilidade: "No horizonte de toda ciência humana há o projeto de reconduzir a consciência do homem a suas condições reais, de restituí-la aos conteúdos e às formas que a fizeram nascer... ${ }^{48 "}$. Portanto, não se trata apenas de situar um discurso no contexto de outros discursos, mas de tematizar as práticas ocultas que estão nas raízes de sua emergência. Desta forma, a consideração de Foucault passa da análise das regras dos discursos (arqueologia) para as próprias condições de sua originação (genealogia) o que significa que os discursos em que o saber se constitui perdem seu lugar privilegiado no pensamento de Foucault. Eles agora fazem parte com outras práticas discursivas de complexos de poder que constituem um campo de objetos específico ${ }^{49}$.

Para Habermas, Foucault com este passo abandonou a autonomia das forças do saber em função de sua fundamentação em tecnologias de poder e submeteu a arqueologia do saber a uma genealogia que explica a originação do saber a partir de práticas de poder. Esta nova proposta teórica

\footnotetext{
${ }^{42}$ Cf. FOUCAULT M., Les mots et les choses, op. Cit., p. 364-365.

${ }^{43}$ Cf. FOUCAULT M., Les mots et les choses, op. Cit., p. 356.

${ }^{44}$ Cf. HABERMAS J., Der philosophische Diskurs der Moderne, op. Cit., p. 316.

${ }^{45}$ Cf. FOUCAULT M., Les mots et les choses, op. Cit., p. 376.

${ }^{46}$ Cf. FOUCAULT M., Les mots et les choses, op. Cit., p. 366.

${ }^{47}$ Cf. HABERMAS J., Der philosophische Diskurs der Moderne, op. Cit., p. 284 e ss.

${ }^{48}$ Cf. FOUCAULT M., Les mots et les choses, op. Cit., p. 375.

${ }^{49}$ Cf. HABERMAS J., Der philosophische Diskurs der Moderne, op. Cit., p. 315-316.
}

\begin{tabular}{|c|c|l|l|c|c|}
\hline intuitio & $\begin{array}{c}\text { ISSN } \\
1983-4012\end{array}$ & Porto Alegre & Vol.7- No.2 & $\begin{array}{c}\text { Novembro } \\
2014\end{array}$ & p. 06-19 \\
\hline
\end{tabular}


lhe permite prosseguir sua crítica à filosofia da subjetividade sem ter que apelar nem para Heidegger nem para o estruturalismo. Para isto o procedimento adequado é uma análise das instituições da sociedade burguesa. No entanto, esta proposta só se sustenta para Habermas porque ele não a pensa genealogicamente.

Nesta perspectiva, uma característica fundamental das análises de Foucault para Welsch ${ }^{50}$ é que para ele a razão não é primariamente coisa de uma faculdade do pensamento, mas uma configuração do poder, um conjunto de estratégias de poder e de processos de disciplinamento. Assim, a racionalidade é o conteúdo real de estruturas sociais, portanto, a fala sobre a racionalidade é eminentemente social, institucional e concreta. A racionalidade é algo pragmático, socialmente incorporado e assim criticável. A razão penetrou na rede das instituições, dos comportamentos, das estratégias e contra-estratégias e impregnou todas as dimensões da sociedade e dos corpos. Por esta razão falar de razão não é em primeiro lugar tarefa da filosofia, mas das ciências sociais já que ela configura a estrutura da sociedade. Aqui os discursos das ciências perdem sua posição privilegiada e formam juntamente com outras práticas discursivas complexos de poder que constituem um campo de objetos especial a ser tematizado pelas teorias do social ${ }^{51}$.

No conceito de práticas ele inclui o momento da influência assimétrica e violenta sobre outros participantes da interação que constitui em última instância intervenções de forças de socialização e organização no substrato natural de criaturas corporais como, por exemplo, julgamentos jurídicos, medidas policiais, castigos, controles, formas de disciplinas corporais e intelectuais, etc. Neste contexto as ciências humanas lhe são de interesse simplesmente enquanto meios que na modernidade reforçam e fazem progredir esse processo incrível de invasão do poder nas interações concretas e corporalmente mediadas ${ }^{52}$.

O problema teórico central aqui a ser trabalhado é o da relação entre discursos e práticas ${ }^{53}$. Por esta razão se vai tornar muito importante a organização do campo de enunciados em que eles aparecem e circulam ${ }^{54}$, pois "não é uma propriedade natural dos discursos que congrega o conjunto de enunciados por ele abarcado na unidade de uma ordem" 55 .

Neste horizonte Foucault vai dirigir cada vez mais sua atenção para a questão da conexão constitutiva entre as ciências humanas e práticas de vigilância o que já se manifesta no fato de que todo discurso se enquadra nos limites de um certo número de exclusões: qualquer pessoa não pode falar de qualquer coisa. O nascimento das clínicas psiquiátricas ou da clínica enquanto tal é exemplar para uma forma de disciplina que ele vai descrever depois como a tecnologia moderna da dominação e que aparece nas formas das fábricas, das prisões, das casernas, da escola, etc.

Nestas instituições totais ele vê monumentos da vitória da "razão regulamentadora" que submete a si não só a loucura, mas também a natureza marcada por necessidades dos organismos singulares e o próprio corpo social de uma população em seu todo. Já em "Loucura e Sociedade Foucault defendeu a tese de que em nossa cultura não existe razão sem loucura, pois razão e loucura são grandezas complementares, fazem parte do mesmo complexo. A história da loucura no tempo da razão mostra justamente que produções de domesticação a razão moderna efetiva. As duas se pertencem de tal modo que quando razão tenta dominar a não razão ela emerge de novo. Isto só se pode entender como jogo de forças ${ }^{57}$.

Para todos estes empreendimentos o elemento determinante é o olhar que separa analiticamente, controla e perpassa tudo, é o olhar do sujeito racional e ao qual, em seu isolamento

\footnotetext{
${ }^{50}$ Cf. WELSCH W. Vernunft. Die zeitgenössische Vernunftkritik und das Konzept der transversalen Vernunft, op. Cit., p. 177-178.

${ }^{51}$ Cf. HABERMAS J., Der philosophische Diskurs der Moderne, op. Cit., p. 316.

${ }^{52}$ Cf. WELSCH W. Vernunft. Die zeitgenössische Vernunftkritik und das Konzept der transversalen Vernunft, op. Cit., p. 174.

${ }^{53}$ Cf. KREMER-MARIETTI A., Introdução ao Pensamento de Michel Foucault, op. Cit., p. 36: "Os discursos, portanto, não devem mais ser considerados como conjuntos de signos, mas como práticas, obedecendo a regras determinadas".

${ }^{54}$ Cf. FOUCAULT M., L'Archéologie du savoir, Paris: Gallimard, 1969,p.75.

${ }^{55}$ Cf. FRANK M., Was ist Neostrukturalismus?, op. Cit., p. 237.

${ }^{56}$ Cf. FOUCAULT M., Histoire de la folie à l'âge classique, Paris: Gallimard, 1972.

${ }^{57}$ Cf. WELSCH W. Vernunft. Die zeitgenössische Vernunftkritik und das Konzept der transversalen Vernunft, op. Cit., p. 167-173.
}

\begin{tabular}{|c|c|l|l|c|c|}
\hline intuitio & $\begin{array}{c}\text { ISSN } \\
1983-4012\end{array}$ & Porto Alegre & Vol.7- No.2 & $\begin{array}{c}\text { Novembro } \\
2014\end{array}$ & p. 06-19 \\
\hline
\end{tabular}


monológico, outros sujeitos só têm acesso no lugar de objetos de uma observação sem participação.

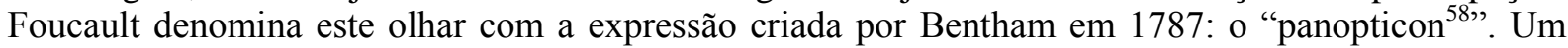
único lugar de observação é suficiente para observar todos os prisioneiros assim que deste lugar central se pode observar simplesmente tudo.

Assim vale: tanto mais luz, esclarecimento e transparência, quanto mais observação, controle e disciplina. A conclusão que Foucault tira daqui é que a razão se transformou em sua própria estrutura numa faculdade da observação e consequentemente de controle universal o que, por sua vez, conduz os indivíduos a uma internalização do controle, ou seja, eles terminam criando mecanismos de autocontrole. A consequência mais radical de tudo é a emergência de uma "sociedade da disciplina" que encontra seu modelo na prisão. A disciplina é, então, o efeito da razão realizada ${ }^{59}$.

Trata-se aqui de uma forma determinada de razão, a razão instrumental, tecnológica, que se tornou hegemônica na modernidade no horizonte da filosofia da subjetividade e é para Foucault uma razão caracterizada por cisões ${ }^{60}$. Neste contexto, contra uma interpretação irracionalista do pensamento de Foucault, Welsch ${ }^{61}$ insiste que as críticas radicais de Foucault se dirigem a este tipo de razão, isto é, a um conceito limitado de razão, até porque com a historificação da razão não tem muito sentido falar da razão como uma grandeza não histórica desvinculada das visões linguísticas de mundo das comunidades históricas. Ao invés de atacar a razão enquanto tal como dizem seus críticos o que Foucault pretende de fato é justamente abrir perspectivas para uma pluralidade de formas fáticas de racionalidade o que pressupõe a quebra do monopólio absoluto da razão instrumental, portanto, em última instância, da centralidade do sujeito na filosofia, um tema central de Heidegger.

Habermas ${ }^{62}$ defende a tese de que há em Foucault sistematicamente um duplo emprego da noção de poder: a) Como "Conceito Descritivo" que se presta a análises empíricas das tecnologias de poder e é um conceito do quadro teórico das ciências sociais; b) Como "Conceito Fundamental Teórico-Constitutivo" que concede às análises empíricas seu sentido racional e o efeito de desmascaramento à forma genealógica de história. É esta ambiguidade sistemática que explica e justifica a vinculação paradoxal entre uma postura positivista e a pretensão crítica que marca os trabalhos de Foucault a partir dos anos 70.

Assim, para Habermas, Foucault pensa a significação do poder juntamente com o sentido transcendental das produções sintéticas de Kant que ele ainda atribuía a um sujeito e que o estruturalismo interpreta como evento anônimo, ou seja, como um operar puramente descentrado, regrado com elementos ordenados de um sistema transubjetivamente construído. Por esta razão na genealogia o poder aparece em primeiro lugar como esta pura atividade estruturalística. Este poder constitutivo do discurso é uma grandeza ao mesmo tempo transcendental e empírica ${ }^{63}$.

Neste contexto, é fundamental para entender a perspectiva em que se encontra Foucault em suas análises levar em consideração a profunda mudança na concepção de poder que ele efetua. Como diz Junges ${ }^{64}$, na modernidade a ideia de poder soberano se referia em primeiro lugar à conquista $\mathrm{e}$ defesa de territórios. A estrutura do governo e o aparato jurídico, que opera com os conceitos fundamentais de lei e contrato, foram assim direcionados para a organização do espaço geográfico. Neste contexto em que se formaram as teorias políticas da modernidade o poder era entendido como concessão individual ao soberano em função do contrato social estabelecido. Neste contexto o Estado

\footnotetext{
${ }^{58}$ Cf. HABERMAS J., Der philosophische Diskurs der Moderne, op. Cit., p. 288.

${ }^{59}$ Cf. WELSCH W. Vernunft. Die zeitgenössische Vernunftkritik und das Konzept der transversalen Vernunft, op. Cit., p. 175-177.

${ }^{60}$ Cf. KREMER-MARIETTI A., Introdução ao Pensamento de Michel Foucault, op. Cit., p. 52: “... a idade clássica, que perdura ainda aos olhos de alguns, opera inegavelmente a separação da linguagem e do mundo, como separa o espírito da matéria, a alma do corpo, assim como procede à separação das "palavras" e das "coisas".

${ }^{61}$ Cf. WELSCH W. Vernunft. Die zeitgenössische Vernunftkritik und das Konzept der transversalen Vernunft, op. Cit., p. 180-187.

${ }^{62}$ Cf. HABERMAS J., Der philosophische Diskurs der Moderne, op. Cit., p. 317-318.

${ }^{63}$ Sobre distinção na modernidade entre estes dois níveis de saber e suas consequências. Cf. FOUCAULT M., Les mots et les choses, op. Cit., p. 256 e ss.

${ }^{64}$ Cf. JUNGES J. R., Biopoder, Biopolítica, in: PAULO BARRETTO V. de/CULLETON A. (orgs.), Dicionário de Filosofia Política, São Leopoldo: Ed. Unisinos, 2010, p. 63.
}

\begin{tabular}{|c|c|l|l|c|c|}
\hline intuitio & $\begin{array}{c}\text { ISSN } \\
1983-4012\end{array}$ & Porto Alegre & Vol.7- No.2 & $\begin{array}{c}\text { Novembro } \\
2014\end{array}$ & p. 06-19 \\
\hline
\end{tabular}


pré-moderno foi fundado no "direito de causar a morte ou deixar viver ${ }^{65 "}$.

Esta perspectiva se foi transformando radicalmente na medida em que o poder foi aos poucos passando da gestão de territórios para a gestão da vida das pessoas. Neste caso, o poder agora não precisa mais ser exercido diretamente pelo soberano, mas através da mediação de inúmeros mecanismos de poder difundidos em todas as esferas da vida coletiva a fim de disciplinar e regulamentar a própria vida biológica dos seres humanos, produzindo subjetividades inteiramente condicionadas até em suas vidas íntimas por estes mecanismos e instituições de controle.

Os gregos distinguiam entre "zoé" que se refere à vida biológica e "bíos" que tem a ver com a vida especificamente humana em sua dimensão ética e política. Até a modernidade a vida física e a saúde eram questões que pertenciam à esfera privada e que, portanto, eram tratadas na esfera das famílias. A grande transformação aconteceu precisamente quando a vida biológica passou a fazer parte do interesse público do Estado e a elaboração do pensamento jurídico se pôs a serviço do poder real na medida em que seu papel essencial consiste em estabelecer a legitimidade do poder e consequentemente a obrigação de obediência a ele $^{66}$.

$\mathrm{Na}$ realidade, o direito entendido como sistema de normas e instituições se fez um grande instrumento de dominação e uma técnica de sujeição para controlar tanto o corpo como a população. Foi este fenômeno que Foucault denominou "biopoder" e foi a partir daqui que ele começou a pensar o poder como uma relação de forças, essencialmente conflitivas, que sempre permeiam a ação social e por isto estão disseminadas em todos os pontos da vida social. É neste sentido que ele vai mostrar a onipresença oculta destas práticas disciplinares de poder nas sociedades liberais contemporâneas uma vez que a "modernidade pressupõe o controle biológico da população como questão de primeira ordem ${ }^{67 "}$.

Para ele isto está profundamente ligado à emergência do capitalismo: "O controle da sociedade sobre os indivíduos não se opera simplesmente pela consciência ou pela ideologia, mas começa no corpo, com o corpo. Foi no biológico, no somático, no corporal que, antes de tudo, investiu a sociedade capitalista. O corpo é uma realidade biopolítica. A medicina é uma estratégia biopolítica ${ }^{68, "}$

Desta forma, este novo poder que Foucault vai chamar de "poder disciplinar", que gerou técnicas de controle cada vez mais eficazes sobre os indivíduos, foi um elemento fundamental para a implantação do capitalismo industrial e da sociedade que corresponde a ele. Isto porque se trata aqui de um mecanismo de poder com novas formas de controle voltadas à saúde do corpo, enquanto força de produção, e à sua conservação o que torna possível tirar dos corpos o máximo de tempo e trabalho e se exerce acima de tudo através da vigilância e se vai apresentar como método de racionalização do próprio exercício de governo ${ }^{69}$.

Numa palavra, o controle dos corpos foi essencial para o desenvolvimento do capitalismo a fim de possibilitar uma relação adequada corpo-produção e por isto a função do poder não é mais matar, mas ao contrário investir sobre a vida uma vez que o capitalismo precisava que os seres humanos fossem potenciados em suas forças e aptidões através da administração dos corpos por meio de técnicas sanitaristas. O poder se faz, assim, gestor da vida ${ }^{70}$, o que se entende até a vida sexual uma vez que a função pro-criativa interessa de perto ao desenvolvimento do sistema. Daí porque se espalharam técnicas de poder em todos os níveis do corpo social utilizadas pelas mais diversas instituições ${ }^{71}$ e a "estatização do biológico" constitui para Foucault um dos fenômenos fundamentais

\footnotetext{
${ }^{65}$ Cf. FOUCAULT M., História da sexualidade 1, Rio de Janeiro: Graal, 1990, p. 150.

${ }^{66}$ Cf. FOUCAULT M., A verdade e as formas jurídicas, $3^{\mathrm{a}}$. Ed., Rio de Janeiro: Nau, 2002, p. 180-181.

${ }^{67}$ Cf. BARROS R., Nietzsche, Foucault e a Biopolítica: uma análise imoral do estado da política, in: ALMEIDA J. C. S. de/MORAES BARROS F. R. de/ GERMANO E. R. (orgs.), Filosofia e Cultura, Fortaleza: Edições UFC,, 2011, p. 254-255.

${ }^{68}$ Cf. FOUCAULT M., Microfísica do Poder, Rio de Janeiro: Ed. Graal, 1984, p. 80.

${ }^{69}$ Cf. FOUCAULT M., Resumo dos cursos do Collège de France (1970-1982), Rio de Janeiro: Zahar Editores, 1997, p. 90.

${ }^{70}$ Cf. SOBRINHO S. F. C. G., Sociedade de controle e o controle da exclusão, in: Filosofia. Unisinos, vol. 8, n.2(2008)166: “As tecnologias do poder _ disciplinar do corpo e regulamentadora da vida _ por serem, como visto, categorias sobrepostas e não se excluírem, podem ser articuladas uma a outra e passam, cada vez mais, a incluir a vida dos homens nos cálculos de poder, transformando a política em biopolítica"

${ }^{71}$ Cf. FOUCAULT M., História da sexualidade: a vontade de saber, 16a ${ }^{\text {a }}$ Ed., São Paulo: Graal, 2005, p. 152.
}

\begin{tabular}{|c|c|l|l|c|c|}
\hline intuitio & $\begin{array}{c}\text { ISSN } \\
1983-4012\end{array}$ & Porto Alegre & Vol.7- No.2 & $\begin{array}{c}\text { Novembro } \\
2014\end{array}$ & p. 06-19 \\
\hline
\end{tabular}


do século XIX, ou seja, justamente a assunção da vida pelo poder ${ }^{72}$.

Ora, Foucault vê esta mesma estrutura presente nas ciências humanas ${ }^{73}$, pois estas ciências podem imbricar-se com tecnologias de poder que se concretizam em terapias e técnicas sociais. Neste sentido se pode compreender sua postura em afirmações em que ele se diz não mais interessado em epistemologia ou teoria, mas numa "analítica do poder" ${ }^{74, "}$. Desta forma as ciências humanas constituem o instrumento mais potente da violência disciplinadora que reina na modernidade, ou seja, elas assumem em nossas sociedades o lugar central do panopticon de onde se vê tudo sem ser visto. É isto o que constitui o "a priori concreto" das ciências humanas: a unidade inseparável entre saber e poder, nelas as práticas de poder assumem o papel transcendental de constituição do saber o que faz com que ao contrário das ciências naturais elas não consigam separar-se de seu contexto de originação. Como diz Habermas ${ }^{75}$, para Foucault as ciências humanas constituem um amálgama entre poder e saber, uma unidade indissolúvel entre formação de poder e formação de saber.

Foucault analisa a vinculação entre saber e estratégias de poder e fala neste contexto do complexo "poder-saber": o saber não é posteriormente vinculado a estratégias de poder, mas se direciona de antemão para o poder em todas as esferas da vida humana já que a vontade moderna de saber determina o conjunto das regras segundo as quais se separa o verdadeiro do falso e marca o verdadeiro com efeitos específicos de poder, vontade que Foucault cada vez mais vai interpretar como vontade de poder. É isto que dá origem ao que ele denomina uma "microfísica do poder ${ }^{76}$ ". Esta postura é o resultado da hegemonia da razão centrada no sujeito que caracteriza a modernidade que conduz ao desaparecimento de relações dialogais e à redução a objetos dos sujeitos encapsulados em si mesmos. Isto leva como ele procura mostrar em muitos exemplos a um parentesco interno entre humanismo e terror. Desta forma, o poder informa o saber, o sistema do saber reproduz o sistema do poder e o projeto genealógico de Foucault de uma escrita da história enquanto anti-ciência tem como objetivo apresentar uma proposta alternativa de saber às ciências humanas vinculadas ao pensamento antropológico da modernidade.

Habermas levanta a pergunta sagaz se ele consegue a partir de uma escrita histórica na forma de arqueologia que depois desembocou numa genealogia efetivar uma crítica radical da razão sem cair nas aporias deste empreendimento auto-referencial. É possível escapar do parentesco entre razão e dominação se o trabalho do historiador é um trabalho racional? O arqueólogo dirige sua atenção aos fundamentos enterrados de sentido, às infraestruturas que com muita dificuldade vêm à tona as quais estabelecem o que no seio de um discurso pode ou não ser considerado verdadeiro. Neste sentido a verdade se revela como um "mecanismo pérfido de exclusão" porque ele só funciona sob a condição de ocultamento de uma vontade de verdade que nele se efetiva. É neste sentido que se pode dizer que Foucault pensa a verdade vinculada ao acontecimento histórico, ao efeito dos jogos de verdade que ocorrem nas práticas concretas ${ }^{77}$.

Neste contexto perdem qualquer valor critérios de validade que nos discursos separam o verdadeiro do falso: pretensões de validade são funcionalisticamente reduzidas a efeitos do poder ${ }^{78}$. Assim estruturas possibilitadoras de verdade não podem ser verdadeiras ou falsas, pois as únicas perguntas possíveis aqui são sobre a função da vontade de verdade que nelas se expressa e sobre a genealogia desta vontade a partir de um feixe de práticas de poder. A genealogia investiga

${ }^{72}$ Cf. FOUCAULT M., Em defesa da sociedade: curso do Collège de France (1975-1976), São Paulo: Martins Fontes, 2002, p. 286.

${ }^{73}$ Cf. MACHADO R., Ciência e saber: a trajetória da Arqueologia de Foucault, Rio de Janeiro: Graal, 1981.

${ }^{74}$ Cf. FLYVBERG B, Esboço de uma ética aplicada ao Desenvolvimento Sustentável: Aristóteles, Foucault e a Phrónesis progressiva, in: Síntese, v. 21, vol. 66 (1994) 346: “... paralelamente à passagem da teoria à análise, há um movimento que vai da pergunta de tendência estrutural sobre o por que do poder à pergunta mais dinâmica sobre o como, i.e., há um movimento da explicação à narrativa".

${ }^{75}$ Cf. HABERMAS J., Der philosophische Diskurs der Moderne, op. Cit., p. 319-320.

${ }_{77}$ Cf. FOUCAULT M., Surveiller et punir. Naissance de la prison, Paris, 1975, p. 32.

77 Cf. CANDIOTTO C., Verdade e Diferença no pensamento de Michel Foucault, in: Kriterion, n. 115 (2007)204: "Para Foucault, a verdade é indissociável da singularidade do acontecimento. Aquilo qualificado de verdadeiro não habita num já-aí; antes, é produzido como acontecimento num espaço e num tempo específicos. No espaço na medida em que não pode ser válido em qualquer lugar; no tempo, porque algo é verdadeiro num tempo propício, num kairós".

${ }^{78}$ Cf. HABERMAS J., Der philosophische Diskurs der Moderne, op. Cit., p. 325.

\begin{tabular}{|c|c|l|l|c|c|}
\hline intuitio & $\begin{array}{c}\text { ISSN } \\
1983-4012\end{array}$ & Porto Alegre & Vol.7- No.2 & $\begin{array}{c}\text { Novembro } \\
2014\end{array}$ & p. 06-19 \\
\hline
\end{tabular}


precisamente como os discursos se formam, porque eles emergem e depois desaparecem enquanto acompanham a gênese de suas condições historicamente variáveis de validade até suas raízes institucionais ${ }^{79}$.

Por esta razão se fazia necessário para Foucault articular "uma teoria geral da descontinuidade, das séries, dos limites, das unidades, das ordens específicas, das autonomias e das dependências diferenciadas ${ }^{80}$ " o que é uma maneira de superar a filosofia da subjetividade, porque "a História

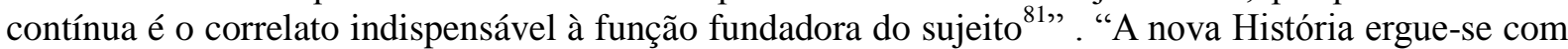
a ajuda dos novos instrumentos epistemológicos que são os conceitos de descontinuidade, de ruptura, de limiar, de limite, de série e de transformação ${ }^{82}$ "...

Certamente isto se situa no contexto geral do pensamento pós-moderno que segundo M. Frank $^{83}$ vê no estruturalismo, apesar de sua crítica à metafísica, traços nitidamente metafísicos na medida em que ele busca princípios universais de ordenação e regularidades universais que tornam o mundo social científico-tecnicamente dominável. O conceito de estrutura do neo-estruturalismo (pensamento pós-moderno) não se vincula à grande tradição ocidental do interesse teórico na dominação, não conhece estas limitações, é um conceito aberto e acessível a infinitas transformações e, portanto, elimina a distinção (saussuriana) que tinha sido determinante no desenvolvimento do estruturalismo clássico entre e sistema (língua) e palavra.

Tudo isto já conduz a um deslocamento de acento no discurso de Foucault. Num primeiro momento, ele tentou desmascarar as ciências humanas unicamente através de uma análise dos discursos. De agora para frente entra em destaque cada vez o conceito de poder. A chave de compreensão aqui é a proposta de Foucault de uma história genealógica. Habermas vê três passos básicos neste empreendimento ${ }^{84}:$ 1) Superação da consciência presentista de tempo da modernidade, ou seja, ele pretende romper com o privilégio do presente que não vai além da situação hermenêutica de seu ponto de partida e pretende estar a serviço da memorização estabilizadora de uma identidade que já desapareceu há tempo. Por esta razão a genealogia não deve buscar uma "origem", mas explicitar os inícios contingentes das formações discursivas, analisar a multiplicidade de históricas fáticas de origem e dissolver a pseudo-identidade o que conduz à dissolução do eu e deixa o lugar livre para milhares de eventos perdidos; 2) A consequência metódica disto é a despedida da hermenêutica: a nova história não está a serviço da compreensão, mas da destruição daquela conexão histórico-efetiva que pretensamente vincula o historiador com um objeto. A genealogia não pretende apropriar-se de sentido, mas se aproximar de fora dos monumentos desenterrados para explicar sua origem a partir de lutas, vitórias e derrotas; 3) Foucault pretende romper definitivamente com uma descrição histórica global que concebe a história como uma macro-consciência. A história no singular deve ser dissolvida no pluralismo de ilhas de discursos que surgem sem regras e depois desaparecem. Daí a eliminação das falsas continuidades e desta forma passam para o primeiro plano as rupturas.

Os resultados da destruição desta forma de fazer história numa perspectiva antropológica é a possibilidade de articular os traços gerais de um 'historicismo transcendental". A atividade de escrever história em Foucault segundo Habermas permanece transcendental no sentido fraco na medida em que ele interpreta os objetos da compreensão de sentido histórico-hermenêutica como objetivações de uma práxis discursiva subjacente a ser captada estruturalisticamente. Desta forma, a arqueologia tem como objetivo explicitar o que cada vez constitui o mundo do discurso, ou seja, suas regras de constituição o que lhe permite tomar consciência das fronteiras do respectivo universo discursivo na medida em que detecta as regras do discurso como mecanismo de exclusão.

Se o espaço da história aparece agora preenchido por eventos simplesmente contingentes do surgir e desaparecer de novas formações discursivas arbitrárias, então, não resta lugar algum para um sentido abrangente. A única hipótese que orienta o historiador neste contexto é: o único que dura é o poder que aparece sob novas máscaras na mudança de processos anônimos de sujeição. É esse processo que substitui a força sintética da consciência transcendental.

\footnotetext{
${ }^{79}$ Cf. HABERMAS J., Der philosophische Diskurs der Moderne, op. Cit., p. 292.

${ }^{80}$ Cf. FOUCAULT M., L'Archéologie du savoir, Paris: Gallimard, 1969,p. 21.

${ }^{81}$ Cf. FOUCAULT M., L'Archéologie du savoir, op. Cit.,p. 2-22.

${ }^{82}$ Cf. KREMER-MARIETTI A., Introdução ao Pensamento de Michel Foucault, op. Cit., p.28.

${ }^{83}$ Cf. FRANK M., Was ist Neostrukturalismus?, op. Cit., p. 36-37.

${ }^{84}$ Cf. HABERMAS J., Der philosophische Diskurs der Moderne, op. Cit.,p. 293 e ss.
}

\begin{tabular}{|c|c|l|l|c|c|}
\hline intuitio & $\begin{array}{c}\text { ISSN } \\
1983-4012\end{array}$ & Porto Alegre & Vol.7- No.2 & $\begin{array}{c}\text { Novembro } \\
2014\end{array}$ & p. 06-19 \\
\hline
\end{tabular}


Nesse contexto, o conceito de poder se transforma no conceito fundamental transcendentalhistórico de uma teoria histórica enquanto critica da razão, ou seja, de um saber que supera as ciências humanas através de uma escrita da história que se revela como anti-ciência que não está tanto preocupada com pretensões de validade dos discursos, mas antes com as regras de sua formação. Enquanto a arqueologia reconstrói a camada das regras que constituem os discursos, a genealogia tenta explicar a sequência não continuada de ordens de signos em si mesmos não fundados que forçam os seres humanos a molduras semânticas de uma determinada interpretação do mundo o que significa explicar a origem das formações discursivas a partir de práticas de poder.

Habermas ${ }^{85}$ vai insistir no fato de que Foucault atribui à genealogia das ciências humanas um duplo papel: a) O papel empírico de uma análise das tecnologias do poder que têm a tarefa de explicar o contexto social funcional das ciências humanas; b) O papel transcendental, cuja tarefa é explicar as condições de possibilidade dos discursos científicos sobre o ser humano. Neste nível, as relações de poder emergem condições de constituição do saber científico. A genealogia tem que ser ambos ao mesmo tempo: ciência social e pesquisa sobre a constituição que se efetiva historicamente. Em ambos os casos é central o conceito de poder.

No entanto, para Habermas o próprio conceito de poder foi obtido a partir do repertório da filosofia da subjetividade, pois aqui o sujeito se põe frente ao mundo de objetos objetiváveis e manipuláveis através de duas relações: a relação cognitiva e a relação prática. Poder é aqui aquilo através de que o sujeito tem sucesso em suas ações sobre os objetos. Isto significa dizer que o conceito de poder não é conceito alternativo às aporias da filosofia do sujeito as quais, aliás, retornam no projeto foucaultiano. Com isto se torna problemático o projeto foucaultiano de superação da filosofia da subjetividade já que ele trabalha com o mesmo esquema conceitual.

Certamente é a partir daqui que se pode entender a proposta de Foucault para a articulação da tarefa da filosofia hoje, ou seja, de se constituir como uma "ontologia do presente ${ }^{86}$. No curso de 1983 sobre o Iluminismo ele afirma: "Parece-me que a escolha filosófica com a qual nós nos encontramos confrontados atualmente é esta: pode-se optar por uma filosofia crítica que se apresentará como uma filosofia analítica da verdade em geral, ou pode-se optar por um pensamento crítico que tomará a forma de uma ontologia de nós mesmos, de uma ontologia da atualidade; é esta forma de filosofia que, de Hegel à Escola de Frankfurt, passando por Nietzsche e Max Weber, fundou uma forma de reflexão dentro da qual tentei trabalhar ${ }^{87}$ ". Que somos nós e que somos nós hoje é a questão de fundo que marca esta tradição de pensamento.

O discurso foucaultiano é marcado segundo Habermas por operações paradoxas: 1) O poder, que nos discursos se oculta enquanto vontade de verdade e ao mesmo tempo se impõe, conserva o sentido transcendental de possibilitador da verdade. Por outro lado, ele temporaliza o a priori kantiano, pensa-o nominalista, materialista e empiricamente, corporal-sensivelmente. Nesta perspectiva ele escapa de todo inteligível e, sobretudo, revela-se como um contingente, que poderia pura e simplesmente ter sido de outro modo. Objeções emergem aqui porque apesar de querer criar uma anticiência ao mesmo tempo pretende proceder erudita e positivisticamente; 2) Foucault manifesta uma profunda decepção com o pensamento de esquerda. Habermas o vê radicalizando aquela figura de pensamento que na modernidade marca os decepcionados: no universalismo do iluminismo, no ideal de emancipação do humanismo, na pretensão de razão do pensamento sistêmico se detecta imbricada uma vontade de poder pouco inteligente. Foucault analisou mecanismos de exclusão que são imperativos de aumento de poder.

A questão de fundo que marca todos esses procedimentos é o confronto radical com a filosofia da subjetividade da modernidade. Foucault interpreta a forma moderna de ciência desde o início

\footnotetext{
${ }^{85}$ Cf. HABERMAS J., Der philosophische Diskurs der Moderne, op. Cit.,p. 323.

${ }^{86}$ O que do ponto de vista da moral o vai levar a considerar como absurda e catastrófica a busca de uma moral de validade universal. Cf. FOUCAULT M., Dits et Écrits, op. Cit., p. 706.

${ }^{87}$ Cf. FOUCAULT M., Dits et Écrits, op. Cit., p. 687-688. Para F. Ortega nesta concentração no hoje está a contraposição radical ao pensamento de Habermas. Cf. ORTEGA F., Habermas versus Foucault. Apontamentos para um debate impossível, in: Síntese, vol. 26 n. 85 (1999)241: "O hoje aparece como tarefa, como acontecimento. A tarefa do pensamento seria realizar uma "ontologia do presente". Voltando a filosofia para a atualidade, o singular, o contingente, o pensamento foucaultiano se encontra nas antípodas da teoria da ação comunicativa habermasiana".
}

\begin{tabular}{|c|c|l|l|c|c|}
\hline intuitio & $\begin{array}{c}\text { ISSN } \\
1983-4012\end{array}$ & Porto Alegre & Vol.7- No.2 & $\begin{array}{c}\text { Novembro } \\
2014\end{array}$ & p. 06-19 \\
\hline
\end{tabular}


marcada pela aporia de que o sujeito cognoscente se eleva dos destroços da metafísica para solucionar na consciência de suas forças finitas uma tarefa que em princípio exige forças infinitas. Assim, a modernidade se caracteriza por essa forma autocontraditória e antropocêntrica de saber de um sujeito de quem se exige algo para além de suas forças. Desse modo, a forma moderna de saber é determinada por uma dinâmica própria e uma vontade de verdade, que precisamente constitui a conexão interna entre saber e poder e é exatamente este o terreno em que se situam as ciências humanas.

No entanto, para Habermas ${ }^{88}$ essa forma genealógica de escrever a história aplicada a si mesma se autodestrói uma vez que o conceito de poder com que trabalha Foucault não concede à sua investigação genealógica a estrutura de um contra-poder capaz de resistir aos efeitos do poder que atuam em todos os discursos. É a consequência de sua tese fundamental: todo contra-poder já se movimenta no horizonte do poder que ele combate e vitorioso se transforma num complexo de poder que provoca um novo contra-poder.

Numa palavra, a genealogia do saber não consegue romper com este círculo mesmo fazendo a tentativa de recuperar o saber desqualificado das vítimas dos mecanismos do poder disciplinar. "A supervalorização ontológica do poder não permitiria conceber uma possibilidade de resistência além das relações de poder ${ }^{89}$ ". Para Habermas, Foucault tem consciência das aporias em que seu pensamento se envolve: o presentismo, o relativismo e a tomada arbitrária de posição, mas não tem resposta a esta problemática ${ }^{90}$.

F. Ortega não só defende a tese da pertinência desta objeção, mas também que Foucault fez em seus últimos anos de vida um deslocamento radical em sua teoria do poder o que vai permitir em sua última fase pensar as lutas de resistência para ampliar os espaços de liberdade ${ }^{91}$. Para ele ocorreu no pensamento de Foucault uma passagem de uma ontologia dupla (saber-poder) para uma tripla (saberpoder-sujeito). O elemento central é a mudança na noção de poder que passa da perspectiva nietzschiana de poder como relação de forças para a ideia de poder como governo.

Este deslocamento foi fundamental para Foucault poder incluir agora o eixo do sujeito e assim passar do governo dos outros ao governo de si mesmo introduzindo a temática da auto-constituição. Agora a teoria não pode mais prescindir de um sujeito definido mediante a relação consigo mesmo. $\mathrm{O}$ sujeito agora não é mais simplesmente o objeto do mecanismo do saber-poder, um simples produto do biopoder, mas vai poder ser pensado como portador de certa autonomia e, portanto, como capaz de resistência. Trata-se de pensar um novo tipo de subjetividade, diferente daquela que foi pensada pela modernidade.

\section{Considerações finais}

Pode-se aceitar com Foucault como tarefa, a partir das aporias da filosofia da subjetividade mostradas pelo próprio Foucault, que a superação da filosofia da subjetividade constitui o grande desafio posto à filosofia hoje. A proposta inicial de Foucault para esta superação elaborada em confronto crítico com o estruturalismo pode ser considerada uma postura anti-realista no sentido de que para ele, como para os anti-realistas, a realidade (o mundo, o universo) não pode ser pensada sem referência a "nossa" linguagem, às "nossas" episteme, a "nossos" sistemas discursivos o que significa dizer que a centralidade da subjetividade persiste de forma transformada.

Daí porque a grande questão aqui e que toca o cerne das filosofias da subjetividade e suas tentativas de superação é a seguinte: estas afirmações implicam manter a subjetividade (ou a intersubjetividade) como instância doadora de sentido a tudo o que significa dizer que ainda se situam no horizonte do pensamento antropocêntrico. Isto nos conduz ao questionamento de fundo em relação ao pensamento de Foucault: em que sentido de fato a postura de Foucault constitui uma alternativa à filosofia da subjetividade?

A passagem da centralidade do sujeito para a centralidade das episteme ou do poder já garante isto? Esta é a grande questão que se põe à filosofia de Foucault e que toca no fundo de sua proposta de

\footnotetext{
${ }^{88}$ Cf. HABERMAS J., Der philosophische Diskurs der Moderne, op. Cit.,p. 327 e ss.

${ }^{89}$ Cf. ORTEGA F., Habermas versus Foucault, op. Cit., p. 242.

${ }^{90}$ Cf. HABERMAS J., Der philosophische Diskurs der Moderne, op. Cit., p. 325-336.

${ }^{91}$ O que defende também Castelo Branco. Cf. BRANCO G. C, Michel Foucault: os Direitos do Homem, op. Cit., p. 153 .
}

\begin{tabular}{|c|c|l|l|c|c|}
\hline intuitio & $\begin{array}{c}\text { ISSN } \\
1983-4012\end{array}$ & Porto Alegre & Vol.7- $\mathrm{N}^{\circ} .2$ & $\begin{array}{c}\text { Novembro } \\
2014\end{array}$ & p. 06-19 \\
\hline
\end{tabular}


pensamento alternativo ao que constitui o cerne do pensamento da modernidade e que assim se revela o pano de fundo a partir de onde se torna possível um diálogo com sua proposta de um penar alternativo.

\section{Referências}

BARROS R., Nietzsche, Foucault e a Biopolítica: uma análise imoral do estado da política, in: ALMEIDA J. C. S. de/MORAES BARROS F. R. de/ GERMANO E. R. (orgs.), Filosofia e Cultura, Fortaleza: Edições UFC, 2011, p. 254-255.

BRANCO G. C, Michel Foucault: os Direitos do Homem, in: AGUIAR O. A./MORAES PINHEIRO C. de/FRANKLIN K (orgs.) Filosofia e Direitos Humanos, Fortaleza: Editora UFC, 2006.

CANDIOTTO C., Verdade e Diferença no pensamento de Michel Foucault, in: Kriterion, n. 115 (2007).

DREYFUS H./RABINOW P., Michel Foucault, uma trajetória filosófica: para além do estruturalismo e da hermenêutica, Rio de Janeiro: Forense Universitária, 1995.

FLYVBERG B, Esboço de uma ética aplicada ao Desenvolvimento Sustentável: Aristóteles, Foucault e a Phrónesis progressiva, in: Síntese, v. 21, vol. 66 (1994).

FOUCAULT M., A verdade e as formas jurídicas, $3^{\mathrm{a}}$. Ed., Rio de Janeiro: Nau, 2002.

, Dits et Écrits 1954-1988, Paris: Gallimard, 1994.

,Em defesa da sociedade: curso do Collège de France (1975-1976), São Paulo: Martins Fontes, 2002.

, História da sexualidade 1, Rio de Janeiro: Graal, 1990.

, História da sexualidade: a vontade de saber, 16ª . Ed., São Paulo: Graal, 2005.

, L'archéologie du savoir, Paris: Gallimard, 1969.

, Le retour de la morale, in: Les Nouvelles, 28.6 e 5.7.1984.

, Les mots et les choses. Une archéologie des sciences humaines, Paris: Gallimard, 1966.

, Microfísica do Poder, Rio de Janeiro: Ed. Graal, 1984.

, Resumo dos cursos do Collège de France (1970-1982), Rio de Janeiro: Zahar Editores, 1997.

, Surveiller et punir. Naissance de la prison, Paris, 1975.

FRANK M., Was ist Neostrukturalismus?, Frankfurt am Main: Suhrkamp, 1983.

HABERMAS J., Der philosophische Diskurs der Moderne. Zwölf Vorlesungen. Frankfurt am Main: Suhrkamp, $2^{\mathrm{a}}$. Ed., 1985.

JUNGES J. R., Biopoder, Biopolítica, in: PAULO BARRETTO V. de/CULLETON A. (orgs.), Dicionário de Filosofia Política, São Leopoldo: Ed. Unisinos, 2010.

KREMER-MARIETTI A., Introdução ao Pensamento de Michel Foucault, Rio de Janeiro: Zahar Editores, 1977. MACHADO R., Ciência e saber: a trajetória da Arqueologia de Foucault, Rio de Janeiro: Graal, 1981.

MARTON S, Foucault leitor de Nietzsche, in: RIBEIRO R. J., Recordar Foucault, São Paulo: Brasiliense, 1985. OLIVEIRA M. A. de, Pós-Modernidade: abordagem filosófica, in: TRASFERETTI J./GONÇALVES P. S.L (orgs.), Teologia na Pós-Modernidade. Abordagens epistemológica, sistemática e teórico-prática, São Paulo:Paulinas, 2003, p. 35.

ORTEGA F., Habermas versus Foucault. Apontamentos para um debate impossível, in: Síntese, vol. 26 n. 85 (1999).

SOBRINHO S. F. C. G., Sociedade de controle e o controle da exclusão, in: Filosofia. Unisinos, vol. 8, n.2(2008).

TERRA R., Foucault leitor de Kant: da Antropologia à Ontologia do presente, in: Analytica, vol. 2, n. 1 (1997). WELSCH W. Vernunft. Die zeitgenössische Vernunftkritik und das Konzept der transversalen Vernunft, Frankfurt am Main: Suhrkamp, 2a. Ed., 1996.

\begin{tabular}{|c|c|l|l|c|c|}
\hline intuitio & $\begin{array}{c}\text { ISSN } \\
1983-4012\end{array}$ & Porto Alegre & Vol.7- No.2 & $\begin{array}{c}\text { Novembro } \\
2014\end{array}$ & p. 06-19 \\
\hline
\end{tabular}

